\title{
Perancangan Interior \\ Perpustakaan Nasional Republik Indonesia
}

\author{
Jalan Merdeka Selatan No.11, Gambir, Kota Jakarta Pusat \\ Asprila Jordi, Adi Ismanto \\ Universitas Tarumanagara \\ asprilajordi@gmail.com, adii@fsrd.untar.ac.id
}

\begin{abstract}
Tujuan penelitian ini ialah untuk mengetahui interior perpustakaan yang baik yang sesuai dengan kegiatan pengguna perpustakaan, mengetahui perpustakaan dengan memperhatikan besaran ruang dan alur sirkulasi yang baik dan mengetahui standar persyaratan teknis dari sebuah perpustakaan. Di Indonesia tingkat minat membaca masyarakat masih rendah. Untuk lebih memacu peningkatan minat baca tersebut maka perpustakaan sebagai gudang ilmu harus dibuat lebih menarik. Salah satu perpustakaan yang menjadi cerminan ilmu pengetahuan di suatu negara adalah Perpustakaan Nasional. Maka dari itu perancangan desain interior pada Perpustakaan Nasional Republik Indonesia harus lebih ditingkatkan. Sehingga dapat disimpulkan jika Perpustakaan yang menarik akan membuat minat berkunjung masyarakat bertambah dan akan mempengaruhi minat baca setiap insan. Perpustakaan Nasional tidak hanya dipandang untuk mewadahi fasilitas edukasi dan informasi saja tetapi dapat membagikan kebudayaan Indonesia kepada pengunjung.
\end{abstract}

Kata Kunci : perpustakaan nasional, desain interior

I. PENDAHULUAN

Pada era globalisasi, bermain dan hangout bersama keluarga, teman maupun rekan kerja, baik di luar rumah maupun kegiatan yang dilakukan di dalam rumah seperti menonton TV, bermain video game dan kegiatan lainnya didalam rumah, balisasi seperti sekarang, perkembangan ilmu pengetahuan makin berkembang pesat dan pola kehidupan masyarakat telah berubah. Masyarakat jaman modern saat ini banyak sekali menghabiskan waktu untuk bekerja sedikit sekali masyarakat Indonesia yang mau meluangkan waktunya untuk membaca buku.
Data statistik UNESCO 2012 yang menyebutkan indeks minat baca di Indonesia baru mencapai 0.001. Artinya, dari 1.000 penduduk hanya satu warga yang tertarik untuk membaca.

Hal ini sangat disayangkan karena membaca merupakan hal yang menyenangkan dan penting dalam menambah wawasan serta pengetahuan, selain itu membaca memiliki fungsi menjadi perantara atau antarmuka (intermediary, interface) antara dunia pengetahuan dan informasi di satu sisi dan pemakai pengetahuan disisi lain (Lancaster, 1979: 4-5)

Indonesia memiliki perpustakaan nasional yang telah dibangun sejak 1980, 
namun perpustakaan sudah tidak sesuai dengan kebutuhan zaman sekarang, maka dari itu permerintah Indonesia membangun perpustakaan nasional dan di resmikan pada tanggal 14 September 2017 oleh presiden Republik Indonesia bapak Ir. H. Joko Widodo. Perpustakaan nasional terletak di Jalan Merdeka Selatan No.11, Gambir dengan keadaan interior yang masih kosong. Selain sebagai tempat yang edukatif, Perpustakaan Nasional Republik Indonesia ini diharapkan dapat menjadi sarana yang rekreatif bagi masyarakat dan dapat menarik pengunjung dari mancanegara sehingga diperlukan rancangan yang menarik dan universal bagi pengunjung sehingga berkeinginan untuk datang mengunjungi perpustakaan.

Perpustakaan yang dirancang harus memperhatikan fungsi ruang agar ruangan tersebut tidak hanya menunjang aktivitas pengunjung, tetapi juga dapat menciptakan suatu sarana atau wadah yang menyediakan berbagai fasilitas relaksasi dengan memperhatikan keindahan ruang agar perpustakaan tidak diartikan sebagai tempat yang membosankan. Selain memiliki fungsi dan estetika yang baik, desain interior harus mampu menunjang interaksi aktivitas para pengguna ruangan tersebut. Perpustakaan Nasional RI didesain harus bernilai estetis secara visual dan dapat menunjukkan imej perpustakaan tanpa mengurangi nilai fungsional.

\section{METODE}

\section{Pendalaman Materi}

a. Studi Pustaka

Merupakan metode perencanaan dengan mencari data-data melalui buku, majalah, skripsi, atau media internet mengenai perpustakaan (berupa pengertian, sejarah, sistem, dan kebutuhan interior perpustakaan).

b. Studi Lapangan

Merupakan metode perencanaan dengan mencari data-data yang terdapat dilapangan untuk mendapat data kelengkapan proyek yang dibutuhkan.

\section{Pengumpulan Data}

a. Wawancara

Merupakan metode perencanaan dengan melakukan kegiatan tanya jawab dengan Ibu Khusnul selaku staff pada bagian Layanan Informasi dan Kunjungan di Perpustakaan Nasional RI. 
b. Observasi lapangan

Metode pengumpulan data untuk mendapatkan informasi dan data dari hasil survey lapangan atau pengamatan langsung di Perpustakaan Nasional RI untuk mendapatkan data yang faktual.

c. Dokumentasi

Metode pengumpulan data secara visual berupa foto dari pengamatan atau observasi langsung di lapangan.

d. Konsultasi Teknis (Asistensi)

Berkonsultasi mengenai permasalahan yang berkaitan dengan proyek yang ditangani untuk menemukan solusi dari permasalahan tersebut, baik kepada dosen pembimbing maupun kepada para ahli lain yang sesuai dengan bidangnya.

\section{HASIL DAN PEMBAHASAN}

1. Area Developer

Perpustakaan Nasional Republik Indonesia memiliki lebar $40.5 \mathrm{~m}$ dan panjang $58.7 \mathrm{~m}$, dikurangi dengan luas 2 core $(12 \mathrm{~m} \times 8.3 \mathrm{~m}) 199.6 \mathrm{~m}^{2}$ total luas keseluruhan bagian dalam bangunan $2.178 \mathrm{~m}^{2} /$ lantai. Total keseluruhan besaran ruang yang dibutuhkan $7.811 .245 \mathrm{~m}^{2}$ sehingga dibutuhkan minimal 4 lantai dari bangunan untuk mencukupi kebutuhan ruang Perpustakaan. Untuk dapat memenuhi kebutuhan 5 tahun kedepannya maka Perpustakaan Nasional Republik Indonesia ditambah 1 lantai sehingga terdapat 5 lantai yang akan di rancang.

2. Konsep Rancangan

Perpustakaan Nasional Republik Indonesia memiliki visi pustaka sebagai ujung tombak kegiatan pelestarian khazanah budaya bangsa menuju terwujudnya khazanah nasional. Menyadari pentingnya khazanah nasional ini, konsep interior perpustakaan mendukung dan mengangkat budaya Indonesia yang kedepannya akan menjadi warisan negara Indonesia. Mengingat bukan hanya pengunjung lokal saja yang datang tetapi juga dari mancanegara. Disinilah kesempatan untuk menunjukan warisan budaya Indonesia. Desain perpustakaan dapat menceritakan kepada pengunjung mengenai warisan budaya yang Indonesia 
miliki.

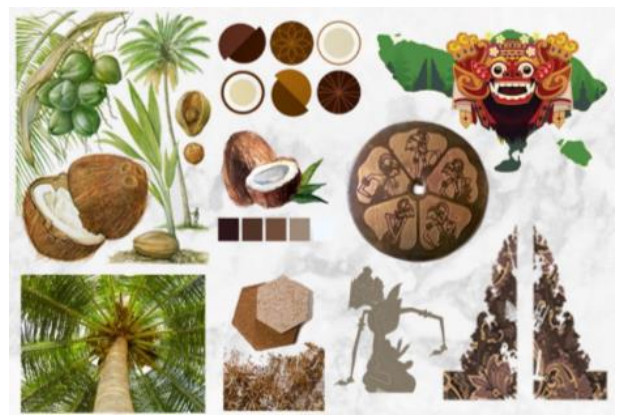

Gambar 1. Konsep Mood Board

3. Konsep Bentuk

Indonesia dengan iklim tropis memiliki luas laut mencapai 7,9 juta $\mathrm{km}^{2}$ dan terdiri dari 13.667 pulau sehingga Indonesia dijuluki negara maritim. Negara yang didominasi dengan pulau memiliki banyak pantai dan salah satu tumbuhan yang dapat hidup di daerah pantai adalah pohon kelapa. Pohon kelapa sangat memiliki banyak manfaat baik dari akar hingga daunnya, banyak masyarakat indoensia yang memanfaatkan pohon untuk kehidupan sehari-hari.

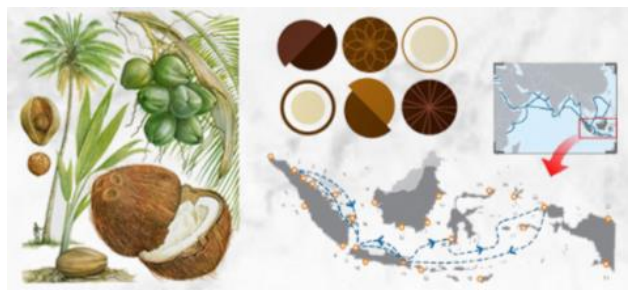

Gambar 2. Konsep Bentuk

4. Konsep Warna

Konsep warna diambil dari warna coklat pada bagian -bagian pohon kelapa. Warna coklat akan digunakan sebagai warna umum yang mendominasi.

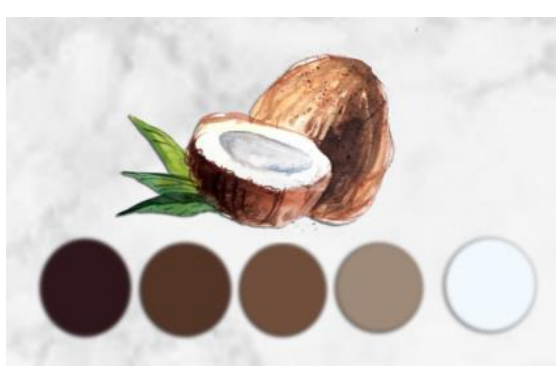

Gambar 3. Konsep Warna

5. Perspektif Ruang

Pemilihan ruang khusus area lobby dan area koleksi monograf terbuka. Pertimbangan pemilihan area lobby secara kuantitatif area lobby memiliki luasan area yang paling besar. Pertimbangan secara kualitatif, first impression pada saat pengunjung masuk Perpustakaan Nasional Republik Indonesia.

Pertimbangan pemilihan koleksi monograf terbuka secara kuantitatif perlunya diperhitungkan dan diperhatikan besaran ruang dari jumlah rak dengan koleksi yang terdapat di Perpustakaan Nasional Republik Indonesia maupun koleksi yang akan bertambah kedepannya.

Pertimbangan secara kualitataif, salah satu fungsi perpustakaan adalah edukasi sehingga kenyamanan, keamanan dan ergonomic ruang koleksi buku perlu diperhatikan secara lebih detail. 
Terdapat tingkat aktivitas yang tinggi pada ruang koleksi buku.

\section{a. Area lobby}

Lobby adalah ruangan yang dimasuki pertama klai oleh para pengunjung. Desain Lobby harus memberikan first impression kepada pengunjung selain main entrance. Area lobby terdiri dari 3 area yaitu area ressepsionis, area bookdrop, dan area lounge.

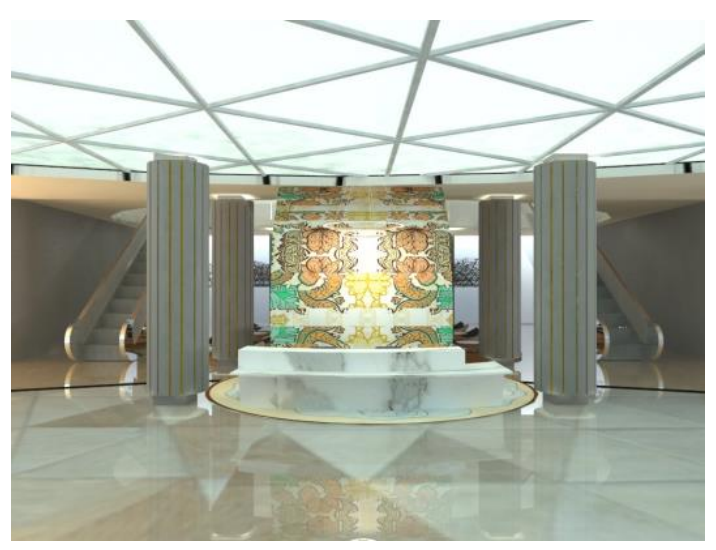

Gambar 4. Area Resepsionis

Area resepionis memiliki luas $317 \mathrm{~m}^{2}$, konsep ceiling barisol, monochrome brown rectangle marmer.

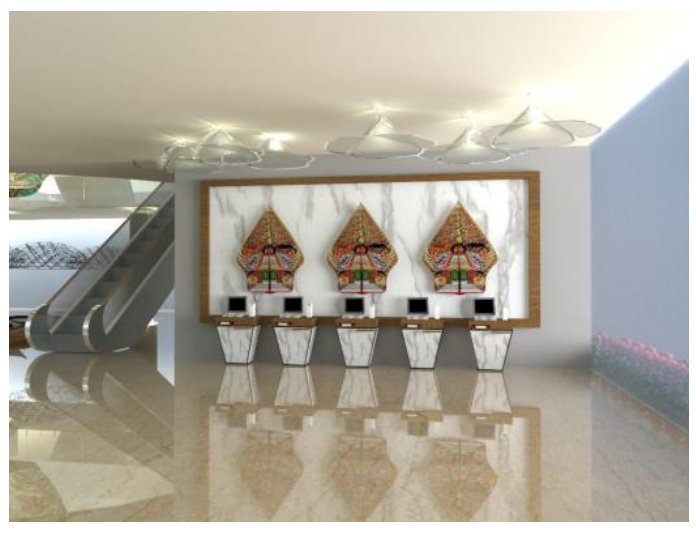

Gambar 5. Area Bookdrop

Area bookdrop memiliki luas $65,6 \mathrm{~m}^{2}$, dengan fasilitas 5 bookdrop, fasilitaas ini diperuntukan bagi para pengunjung yang ingin mengembalikan buku tanpa harus naik ke lantai atas. Konsep dekorasi lighting diambil dari puspa bangsa yaitu bunga melati. Pada dinidng terdapat dekorasi gunungan yan memiliki arti rumah diharapkan pengguna perpustakaan dapat merasa nyaman seperti berada di rumah.

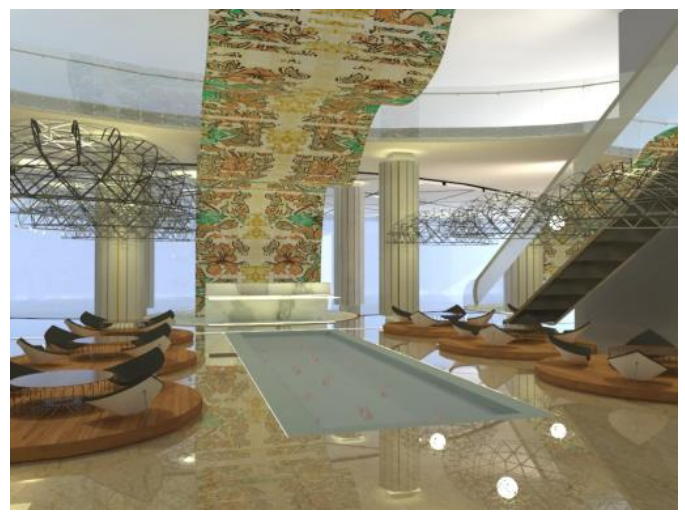

Gambar 6. Area Lounge

Area lounge memiliki luas $97,5 \mathrm{~m}^{2}$, dengan kapasitas 24 pengunjung, dan konsep furniture yang digunakan terinspirasi dari buah kelapa dengan gaya kontemporer.

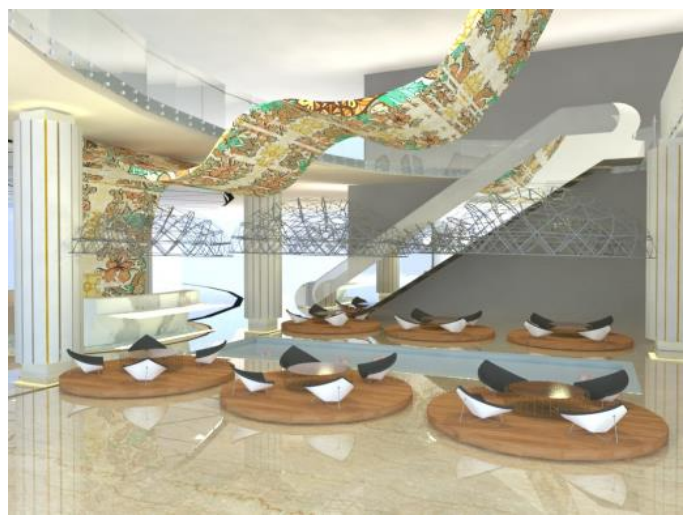

Gambar 7. Area Lounge

Konsep kertas terbentang dari lantai 1 hingga lantai 5 bagaikan menceritakan 
khasanah budaya Indonesia. Ukiran batik di terapkan secara manual (dilukis), menggunakan proyektor dan hologram yang melambangkan Indonesia maju dalam sisi teknologi.

b. Area Koleksi Monograf Terbuka

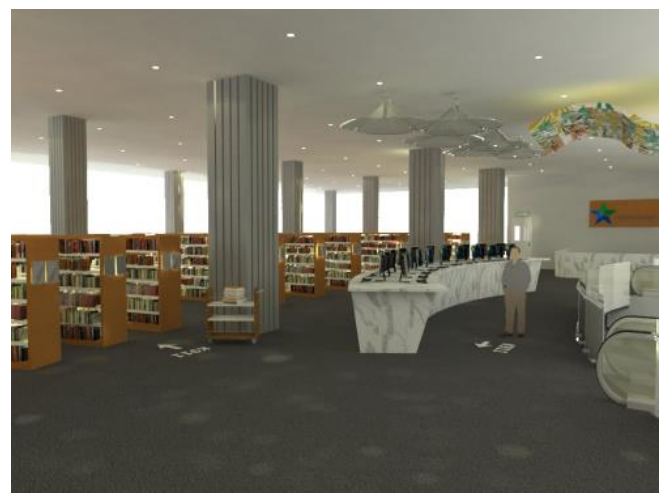

Gambar 8. Area Katalog

Area Meja Katalog Monograf Terbuka memiliki luas 131,2 $\mathrm{m}^{2}$, dengan luminous karpet yang bukan hanya sebagai peredam pada bagian lantai tetapi juga sebagai petunjuk arah pencarian buku, daylight sensor pada konsep lighting agar cahaya yang letaknya dekat dengan kaca dan dibagian dalam setara mencapai 300 lux dan penggunaan metal halide pada kaca agar cahaya matahari tidak langsung masuk area koleksi.

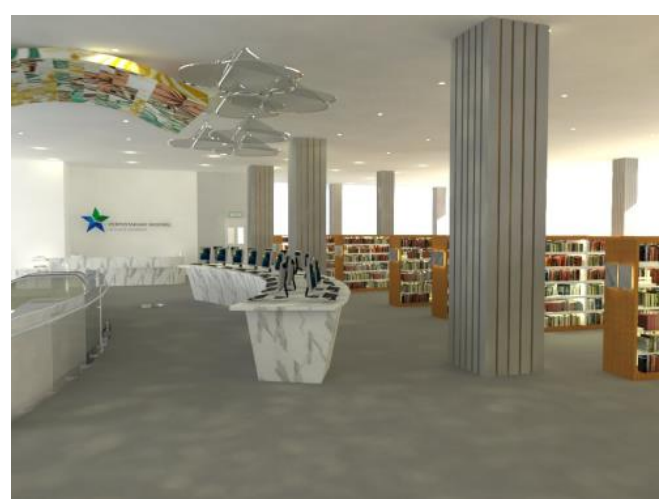

Gambar 9. Area Katalog

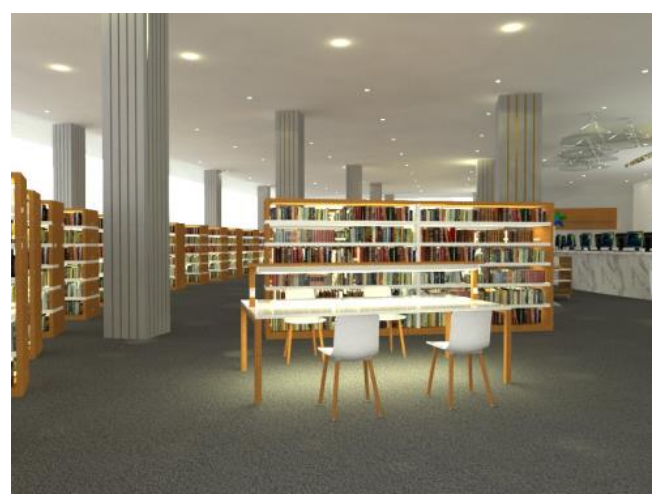

Gambar 10. Meja Baca Sementara

Area Meja Baca Sementara memiliki luas $65,6 \mathrm{~m}^{2}$.

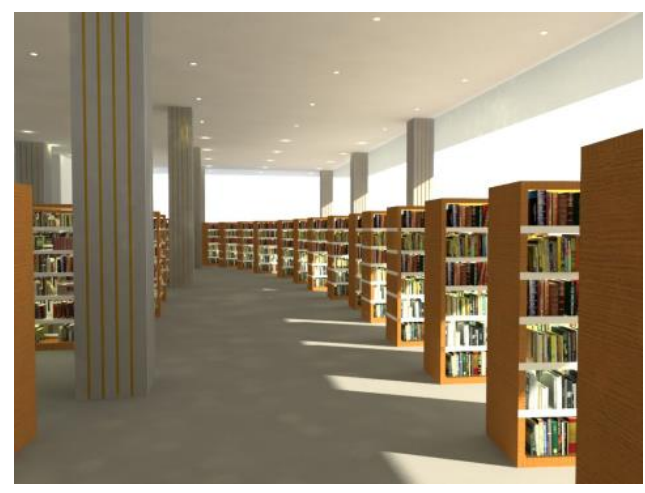

Gambar 11. Lorong Koleksi Buku

Area Lorong Katalog Monograf

Terbuka memiliki luas $769.8 \mathrm{~m}^{2}$. 


\section{SIMPULAN}

Perancangan Interior Perpustakaan

Nasional Republik Indonesia memiliki fungsi edukasi, rekreatif, informatif dan layanan pustaka. Visi perpustakaan yaitu, "Pelestarian khazanah budaya bangsa menuju terwujudnya khazanah nasional." Konsep interior perpustakaan mendukung dan mengangkat budaya Indonesia yang nantinya akan menjadi warisan bangsa. Konsep ini memperkenalkan kepada pengunjung baik lokal maupun mancanegara mengenai kekayaan budaya Indonesia.

Perancangan ini memiliki keterbatasan yaitu penggunaan kaca metal halida pada dinding bangunan perpustakaan tidak dapat menyesuaikan cahaya matahari yang masuk.

Oleh karena itu pada perancangan selanjutnya diharapkan menggunakan bahan material dengan teknologi yang lebih baik untuk dinding bangunan perpustakaan.

\section{UCAPAN TERIMA KASIH}

Puji syukur kepada Tuhan Yesus Kristus atas berkat dan penyertaan-Nya selama ini, sehingga pada akhirnya dapat menyelesaikan tugas akhir. Pada kesempatan kali ini penulis mengucapkan terima kasih kepada tim pembimbing karya tugas akhir Program Studi Interior yang telah membantu dalam penulisan jurnal ini dan memberikan dukungan, saran dan semangat dalam proses perancangan tugas akhir. Selain itu ucapan terima kasih ditujukan kepada pihak Perpustakaan Nasional Republik Indonesia yang telah memberikan izin untuk penggunaan lokasi dan keperluan dokumentasi.

\section{DAFTAR PUSTAKA}

Basuki, Sulistyo. Pengantar IImu Perpustakaan. Jakarta: Universitas Terbuka, 2003.

Darmono. Manajemen dan Tata Kerja Perpustakaan Sekolah. Jakarta: Grasindo, 2001.

Edwards, Brian dan Biddy Fisher. Libraries and Learning Resource Centres. New York: Architectural Press, 2002.

HS, Lasa. Jenis - Jenis Pelayanan Informasi Perpustakaan. Yogyakarta: Gajah Mada University Press, 1995.

HS, Lasa. Manajemen Perpustakan Sekolah. Yogyakarta: Pinus Book Publisher, 2007.

Kilmer, Rosemary \& Otie Kilmer. Designing Interiors. USA: Wadsworth, Thomson Learning, 1992.

Mc Gowan, Maryrose, Interior Graphic Standards, John Wiley \& Sons, 2003. 
Moedjono, Parlinah. Perpustakaan Perguruan

Tinggi. Dep. Pendidikan dan Kebudayaan Republik Indonesia, 1994.

Mulyani A Nurhadi. Sejarah Perpustakaan dan

Perkembangannya di Indonesia.

Yogyakarta: Andi Offset, 1983.

Neufert, Ernst. 1996. Data Arsitek. Jilid 1. Edisi

Kedua. Jakarta: Penerbit Erlangga.

NS, Sutarno. Seperempat Abad Perpustakaan

Umum Pemerintah Provinsi Daerah Khusus Ibukota Jakarta, Jakarta:

Pustaka Sinar Harapan, 2003.

NS, Sutarno. Perpustakaan dan Masyarakat. Jakarta: Yayasan Obor Indonesia, 2003.

Panero, Julius dan Martin Zelnik. Dimensi Manusia \& Ruang Interior. Jakarta: Erlangga, 2003.

Perpustakaan Nasional Republik Indonesia. Petunjuk Teknis Pelestarian Bahan Pustaka. Jakarta: Perpustakaan Nasional Republik Indonesia, 1995.

Perpustakaan Nasional Republik Indonesia.

Standart Nasional Perpustakaan. Jakarta: Perpustakaan Nasional Republik Indonesia, 2011.

Poore, Jonathan. Interior Color by Design. USA: Rockport Publisher. 1994.

Pusat Pembinaan Perpustakaan. Pedoman Penyelenggaraan Perpustakaan Umum. Jakarta: Departemen Pendidikan dan Kebudayaan, 1982.
Soetminah, Perpustakaan, Kepustakawanan dan Pustakawan. Yogyakarta: Kanisius, 1992.

Sumardji,P. Perpustakaan Organisasi dan Tata Kerjanya. Yogyakarta: Kanisius, 1988.

Supriyanto. Aksentuasi Perpustakaan dan Pustakawan, Jakarta: Ikatan Pustakawan Indonesia Pengurus Daerah DKI Jakarta, 2006.

Suwarno, Wiji. Dasar - Dasar IImu Perpustakaan. Yogyakarta: Ar-Ruzz, 2010. 